\title{
Wheezing in childhood: incidence, longitudinal patterns and factors predicting persistence
}

\author{
P.M. Matricardi*, S. Illï, C. Grüber*, T. Keil", R. Nickel*, \\ U. Wahn* and S. Lau*
}

ABSTRACT: Childhood asthma is frequently perceived as a disease with uniform clinical pathways. This perception might be an oversimplification. The aim of the present study was to investigate the incidence and natural course of wheeze over the first 13 yrs of life and analyse the risk factors predicting wheeze at 11-13 yrs of age.

The Multicentre Allergy Study, a German birth cohort, recruited 1,314 children in 1990. Physical examinations, interviews on atopic diseases, immunoglobulin (Ig)E and lung function tests were performed up to 13 yrs of age.

Complete data on the course of wheeze were available for 441 children. It was found that incidence of wheezing declined with age. The first wheezing episode was reported by 29, 9 and $9 \%$ of participants at $\leqslant 3$ (early wheezers), 3-6 (late wheezers), and $>6$ yrs (very late wheezers) of age, respectively. Wheezing at the age of 13 yrs was associated with parental atopy, and with IgE sensitisation to common allergens, elevated total $\operatorname{lgE}$ and exposure to high levels of indoor allergens in early life. All these associations were remarkably stronger among early wheezers than among early nonwheezers.

In conclusion, the relevance of an early expression of atopy as a predictor of wheezing at age 13 yrs declines with increasing age of wheezing onset.

KEYWORDS: Asthma, atopic dermatitis, children, epidemiology, prediction of persistence, wheezing

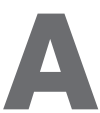
sthma and other wheezing disorders are among the most common childhood diseases [1]. Understanding of the genetic, environmental and developmental factors of childhood asthma is essential for the development of tools for predicting and, hopefully, preventing recurrence of wheezing episodes and subsequent deficits in airway function growth [2,3]. Algorithms to predict asthma in wheezing children have been developed on the basis of observational longitudinal studies [4-7], with the most popular algorithm targeted to predict asthma in children who start wheezing before 3 yrs of age [4]. However, many children start wheezing only after the age of 3 yrs; if atopy and other risk factors for asthma in these children are different from those predicting asthma among early wheezers, then additional algorithms should be formulated. The airways of children with early wheezing may be more susceptible to the negative consequences of an early sensitisation and exposure to allergens. Therefore, the present authors hypothesised that atopy and other risk factors may have a different impact on the natural history of wheezing disorders in children according to their propensity to wheeze. In order to test this hypothesis, data from the German Multicentre Allergy Study (MAS), a prospective observational birth cohort study followed up until 13 yrs of age [8], were analysed. On the basis of the present findings, a description of the natural course of wheezing up to 13 yrs of age in the MAS cohort is provided and a comparative analysis of the risk factors predicting wheeze at age 11-13 yrs in children both wheezing and not wheezing in the first 3 yrs of life is performed.

\section{METHODS}

\section{Study population}

The German MAS recruited 1,314 infants born in 1990 in six German obstetric departments in five German cities (Dusseldorf, Mainz, Freiburg, Gaisach, Berlin). A detailed description of the stratified sampling scheme and study subjects is given elsewhere [8]. Briefly, 499 newborns with
AFFILIATIONS

*Dept of Paediatric Pneumology and Immunology,

"Institute for Social Medicine

Epidemiology and Health Economics, Charité University Medical Centre,

Berlin, and

\#University Children's Hospital,

Munich, Germany.

CORRESPONDENCE

P.M. Matricardi

Dept of Paediatric Pneumology and Immunology

Charité - Universitätsmedizin

Augustenburger Platz 1

D-13353 Berlin

Germany

Fax: 4930450559931

E-mail: paolo.matricardi@charite.de

Received:

June 012007

Accepted after revision:

April 272008

\section{SUPPORT STATEMENT}

The present study was supported by the German Ministry of Education and Research (BMBF), grant number 01 EE9406.

STATEMENT OF INTEREST

None declared. 
presumed risk factors for atopy (cord blood immunoglobulin (Ig)E increased to $\geqslant 0.9 \mathrm{kU} \cdot \mathrm{L}^{-1}$, at least two atopic family members, or both) and 815 newborns with none of these risk factors were included in the cohort. All children were followed up at $1,3,6,12,18$ and 24 months, and then annually, within 4 weeks of the child's birthday, up to the age of 13 yrs. The present study was approved by the hospital's ethics committee (University Children's Hospital, Munich, Germany) and written informed consent, at the time of enrolment, was obtained from the child's parents.

\section{Parental questionnaires and interviews}

At each follow-up visit, parents either gave structured interviews to a study physician or completed postal questionnaires (at age 8,9,11 and 12 yrs). The main topics of these interviews were asthmatic and atopic symptoms and disease; questions on diet, development and psychological aspects were also included. From age 5 yrs onwards, questions relating to wheeze corresponded to the International Study of Asthma and Allergies in Childhood core questions [9]. Foremost interest was in atopic symptoms and diseases. Furthermore, symptoms and diagnoses of other illnesses were assessed at every follow-up, as were maternal breast-feeding and feeding practices up to age 2 yrs. Parental smoking habits were assessed at age 1 month and pet keeping was assessed at age 3 months. Furthermore, the use of medication was assessed at every follow-up. Children regularly visited a physician independent of the study team.

\section{Definitions}

Wheeze was defined as any parent-reported wheezing in the 12 months prior to any of the follow-ups. The definitions "early wheezers" and "late wheezers" were used to describe the children starting wheezing before 3 yrs of age and at 36 yrs of age, respectively [10]. Children who started wheezing only after 6 yrs of age were defined as "very late wheezers". Early wheezers were further classified on the basis of the recurrence of wheezing between 4 and 13 yrs of age; they were defined as: "early persistent wheezers" if they continued to wheeze every year up to the age of 13 yrs; "early intermittent wheezers" if they wheezed in some years but not in others between 3 and 13 yrs of age; and "early remittent wheezers" if they did not wheeze from 3 yrs up to the age of 13 yrs. For the purposes of the univariate and multivariate analyses, children not wheezing before the age of 3 yrs were defined as "early nonwheezers". Parental atopy was defined as any reporting of asthma, hay fever or atopic dermatitis ever. Early atopic dermatitis was defined as present if the parents reported at least one of the following up to the age of 2 yrs: a reported diagnosis by the family physician; a parental reporting of symptoms of atopic dermatitis; or visible atopic dermatitis at the time of follow-up. In order to exclude very mild cases of atopic dermatitis, only children with parental reports of self-scratching were included in the definition of atopic dermatitis [11]. Lower respiratory tract infections in the first 3 yrs of life were defined on the basis of parental reports of symptoms and diagnoses [12].

\section{Cord blood, total and specific IgE}

Serum samples were obtained from the children at birth and at $1,2,3,5,6,7$ and 10 yrs of age. Cord blood $\operatorname{IgE}$, total $\operatorname{IgE}$ and specific IgE antibodies to food allergens (cow's milk, egg white, soy bean and wheat) and inhalant allergens (house dust mite (Dermatophagoides pteronyssinus), cat dander, mixed grass and birch pollen) were determined by using ImmunoCAP (Phadia, Freiburg, Germany). Sensitisation to a specific allergen was defined as a concentration $\geqslant 0.70 \mathrm{kU} \cdot \mathrm{L}^{-1}$ of the respective specific IgE (ImmunoCAP class 2). This cut-off was chosen to constitute a stronger atopic effect than would have been by merely choosing evidence of any detectable specific IgE, i.e. ImmunoCAP class 1 . Increased cord blood $\operatorname{IgE}$ was defined as a concentration of $\geqslant 0.9 \mathrm{kU} \cdot \mathrm{L}^{-1}$, and increased total IgE at age $3 \mathrm{yrs}$ was defined as a concentration $\geqslant 30.0 \mathrm{kU} \cdot \mathrm{L}^{-1}$. This cut-off was based on the upper standard deviation limit of an equivalent aged normal infant population [13].

\section{Assessment of indoor allergen exposure}

At the ages of 6 and 18 months and 3, 4 and 5 yrs, Der p 1, Der f 1 , and Fel d 1 allergens were extracted from dust samples collected by parents from the carpet and analysed with a sandwich ELISA (ALK, Copenhagen, Denmark) [14, 15]. High level of exposure to a specific allergen at a specific age was defined as a measured value above the third quartile of the respective distribution in the total population.

\section{Statistical analysis}

Chi-squared tests were used to compare prevalence between groups and Mantel-Haenszel tests were used for analysing trends over categories. Generalised estimation equation models were used in order to adjust for repeated measures in the analysis of the effect of early childhood factors on wheezing at age 11, 12 and 13 yrs. Data are presented as odds ratios (ORs) and $95 \%$ confidence intervals (CI). All factors significant in univariate analysis were included in a stepwise procedure to elicit a final model. In order to take the stratified sampling scheme and a possible participation bias into account, all multivariate models were adjusted for parental atopy. Furthermore, sensitivity, specificity, and positive and negative predictive values of various early life factors were calculated for the outcome of wheezing at the age of 11, 12 or 13 yrs. For analyses on the incidence and natural course of wheeze over time, all children with complete data on wheeze up to the respective time point of analysis were included in the analyses. For all other analyses, all children with data on early wheeze were included.

\section{RESULTS}

\section{Study population and response rates}

Of the 1,314 enrolled children, 441 (33.6\%) had information on wheeze for every year of the follow-up until age 13 yrs (fig. 1). For 391 (88.7\%) of these children, data on specific IgE in the first 3 yrs of life were available. In order to assess potential participation bias, the study population of 441 children was compared with children with incomplete data on the course of wheeze based on data collected at birth (table 1). No significant differences were found with respect to parental history of atopy, sex, cord-blood IgE, older siblings or parental education. However, children in the study population were more likely to have nonsmoking parents $(\mathrm{p}<0.001)$. Furthermore, the study population of 441 children was compared with children with complete data up to the age of 3 yrs and incomplete data thereafter, based on data collected in the first years of life. No significant differences were found with respect to early atopic 


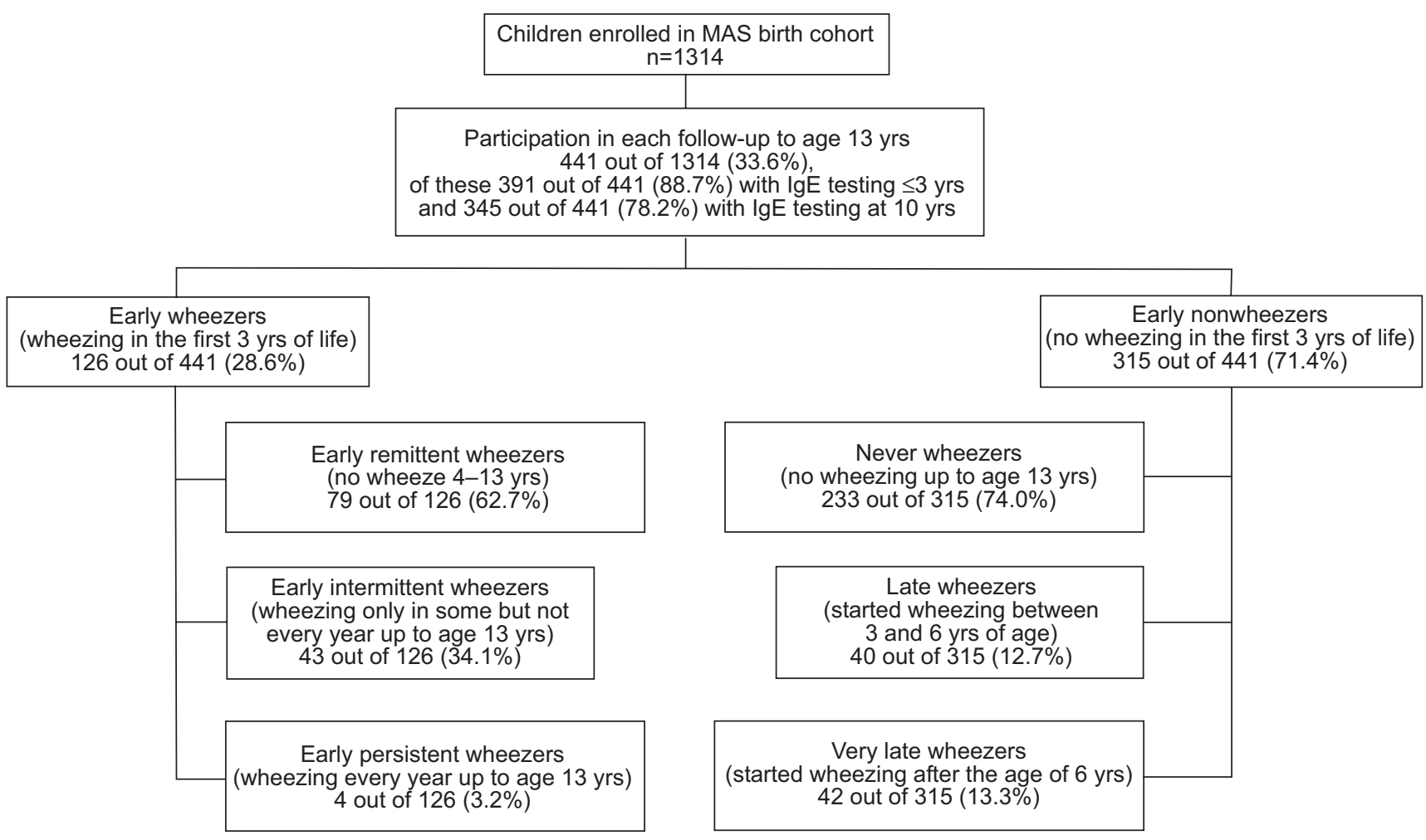

FIGURE 1. Schematic of the Multicentre Allergy Study (MAS) cohort, including response rates, drop-out and longitudinal pattern of wheezing. Ig: immunoglobulin.

dermatitis, early wheeze and early atopic sensitisation. However, children in the study population were more likely to be breastfed for at $\geqslant 4$ weeks $(p=0.020)$. A detailed description of the population sample is reported elsewhere [14].

\section{Incidence of first wheezing episode from birth to 13 yrs of age}

In total, $80(18 \%)$ children out of the study population of 441 wheezed in the first year of life. The incidence of new wheeze

TABLE 1 Characteristics at birth and in the first years of life in children with complete data on the course of wheeze from birth to age 13 yrs compared with children with incomplete data on the course of wheeze

\section{Children with complete data on the course of wheeze from birth to age 13 yrs (study population)}

\section{Children with incomplete data on the course of wheeze from birth to age 13 yrs}

Children with complete data on the course of wheeze up to age 3 yrs, but with incomplete data on the course thereafter

\section{Subjects $\mathbf{n}$}

441

873

515

\section{Data collected at birth}

Parental history of atopy

Male sex

Elevated cord blood IgE $\left(\geqslant 0.9 \mathrm{kU} \cdot \mathrm{L}^{-1}\right)$

$\geqslant 1$ older sibling

Parental smoking

Higher level of parental education

Data collected in the first years of life

Early atopic dermatitis $\leqslant 2 y r s$

Early wheeze $\leqslant 3$ yrs

Atopic sensitisation age 2 yrs (ImmunoCAP class I)

Breastfed $\geqslant 4$ weeks

$\begin{array}{cc}240 / 440(54.5) & 443 / 867(51.1) \\ 234 / 441(53.1) & 450 / 873(51.5) \\ 75 / 421(17.8) & 166 / 840(19.8) \\ 194 / 441(44.9) & 399 / 872(45.8) \\ 161 / 403(39.9) & 411 / 787(52.2)^{\star \star \star} \\ 240 / 422(56.9) & 423 / 807(52.4)\end{array}$

$108 / 441(24.5)$

$104 / 515(20.2)$

$126 / 441$ (28.6)

67/283 (23.7)

$347 / 439$ (79.0)
$173 / 515$ (33.6)

$87 / 318(27.4)$

$370 / 510(72.5)^{*}$

Data are presented as $n / n$ total (\%), unless otherwise stated. Ig: immunoglobulin. *: $p<0.05$ compared with children with complete data on the course of wheeze up to age 13 yrs; ${ }^{* *}: \mathrm{p}<0.001$ compared with children with complete data on the course of wheeze up to age 13 yrs. 


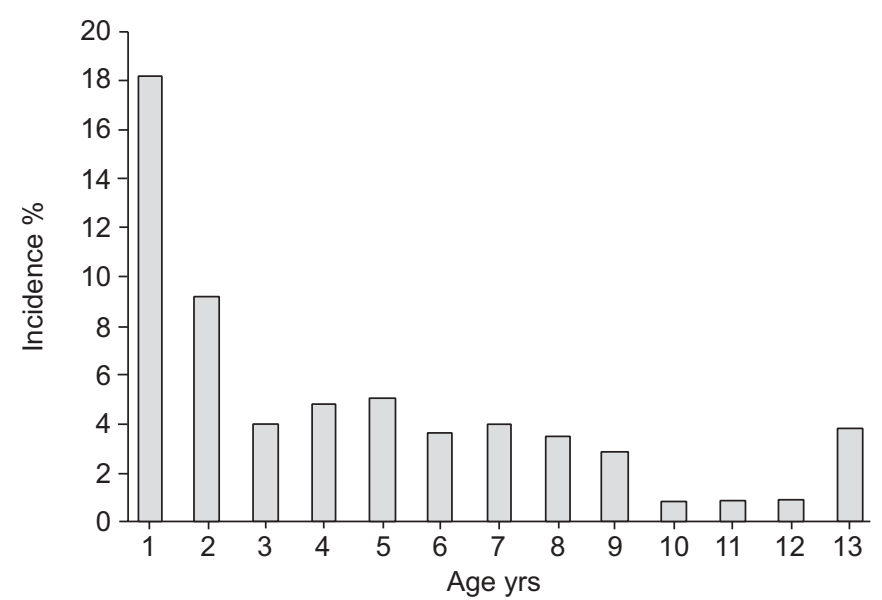

FIGURE 2. Incidence of wheezing up to the age of $13 \mathrm{yrs}$ in the German Multicentre Allergy Study cohort.

sharply declined in the second (33 (9\%) out of 361) and third year of life (13 (4\%) out of 328). Overall, $126(29 \%)$ out of 441 of the children in the MAS cohort started wheezing in their first 3 yrs of life (early wheezers). The incidence of new wheezing disorders was stable thereafter up to 7 yrs of age at $\sim 4 \%$ (range $3.5-5.0 \%$ ). Then the incidence further declined to $<1 \%$ at $10-12$ yrs and abruptly rose again at 13 yrs to about $4 \%$ (fig. 2). Overall, $40(9 \%)$ out of the population sample of 441 started wheezing between 3 and 6 yrs of age (late wheezers) and another $42(9 \%)$ out of 441 started wheezing after 6 yrs of age (very late wheezers).

\section{The natural course of wheezing}

Six different longitudinal patterns of wheezing in the population sample were distinguished (fig. 1). Among early wheezers, remission of symptoms after early childhood was very high: 79 (63\%) out of 126 did not wheeze after the age of 3 yrs, (early remittent wheezers); 43 (34\%) out of 126 continued to wheeze after the age of 3 yrs but not every year (early intermittent wheezers); and only 4 (3\%) out of 126 of the early wheezers continued wheezing every single year from birth up to age 13 yrs. Among children who never wheezed before the age of 3 yrs: 233 (74\%) out of 315 also did not wheeze up to the age of 13 yrs (never wheezers); 40 (13\%) out of 315 started wheezing between 3 and 6 yrs of age (late wheezers); and 42 (13\%) out of
315 started wheezing after the age of 6 yrs (very late wheezers). Overall, the prevalence of children wheezing at age 11,12 or 13 yrs was $22 \%$ (28 out of 126) among early wheezers and only $10 \%$ (31 out of 315) among early nonwheezers. Among these 59 children wheezing at age 11-13 yrs, 28 (47\%) of them were early wheezers, $6(10 \%)$ were late wheezers and $25(42 \%)$ were very late wheezers.

The frequency of an atopic family background, early sensitisation and current sensitisation was analysed in relation to the six different longitudinal patterns of wheezing (table 2). The prevalence of atopy at 3 yrs of age was very low among never wheezers (12\%), low among early remittent wheezers and very late wheezers (both 19\%), intermediate among late and early intermittent wheezers (32 and 36\%, respectively) and high among early persistent wheezers $(75 \%)$. The prevalence of atopy at $10 \mathrm{yrs}$ of age was low among never and early remittent wheezers (27 and 30\%, respectively), intermediate among late and very late wheezers (45 and 53\%, respectively) and highest among early intermittent and early persistent wheezers (69 and 75\%, respectively). Interestingly, among very late onset wheezers, the prevalence of early sensitisation was relatively low $(18.7 \%)$, whereas sensitisation at age 10 yrs was moderately high (53.1\%; table 2$)$.

\section{Different patterns of risk factors for wheezing at the age of 13 yrs}

The association of early atopic sensitisation (and related risk factors) with wheezing at 11-13 yrs of age in children wheezing or not wheezing before 3 yrs of age was examined (table 3 ). In the MAS cohort, cat and/or mite exposure and sensitisation were strongly linked [14] and their concurrence contributed to a reduced lung function at school age [16]; therefore, in the present study, their interaction in the multivariate analysis was accounted for. In univariate analysis, the spectrum of early-life risk factors associated with wheezing at age 13 yrs was remarkably broader in early wheezers than in early nonwheezers; indeed, among early wheezers, wheezing at puberty was associated with parental asthma, hay fever and atopic dermatitis, allergic sensitisation against food or airborne allergens, elevated total IgE and early atopic dermatitis. In contrast, among early nonwheezers, wheezing at puberty was significantly associated with only parental hay fever and asthma, sensitisation to indoor allergens, and early atopic dermatitis. In addition, the strength of the associations

TABLE 2 Parental atopy, sex and atopy in children with different longitudinal patterns of wheezing from birth to age 13 yrs

Total subjects $\mathbf{n}$

Parental atopy

$77 / 125(61.6)$

$41 / 78(52.6)$

$32 / 43(74.4)$

$4 / 4(100.0)$

$24 / 40(60.0)$

28/42 (66.7)

$111 / 233(47.6)$
Male sex

Atopy $\leqslant 3$ yrs

$31 / 116(26.7)$

$14 / 73(19.2)$

$14 / 39(35.9)$

$3 / 4(75.0)$

$11 / 34(32.3)$

$6 / 32(18.7)$

26/209 (12.4)
Atopy $10 \mathrm{yrs}$

$47 / 103(45.6)$

19/63 (30.2)

25/36 (69.4)

$3 / 4(75.0)$

$15 / 33(45.4)$

$17 / 32(53.1)$

$48 / 177(27.1)$ 
TABLE 3 Risk factors for wheezing at age 11-13 yrs by age at onset: results of unadjusted and adjusted ${ }^{\#}$ generalised estimation equation models

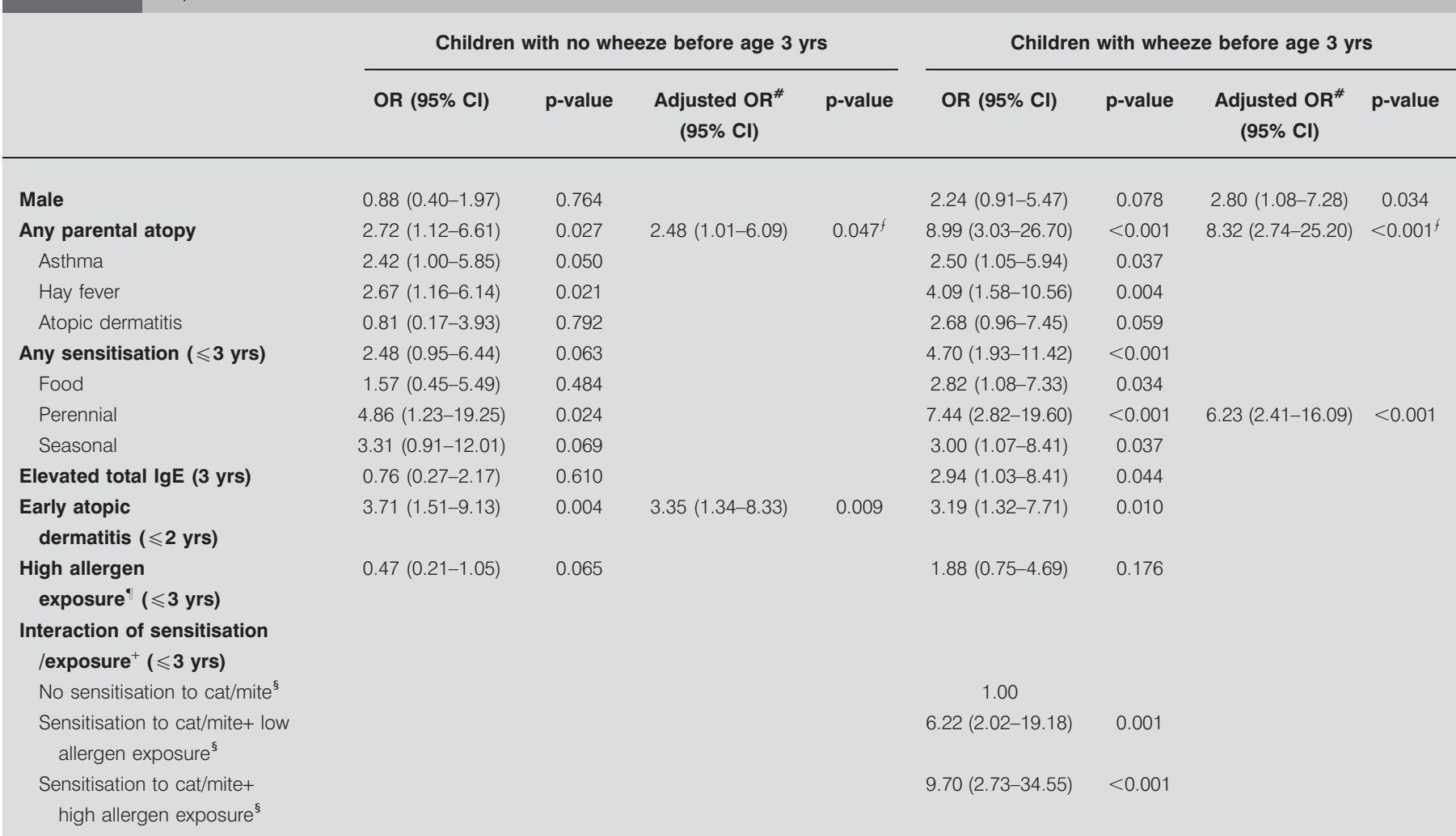

OR: odds ratio; $\mathrm{Cl}$ : confidence interval; Ig: immunoglobulin. ${ }^{*}$ : mutually adjusted for each of the listed factors; $"$ : exposure to cat or mite allergen $\leqslant 3$ yrs in the upper quartile of the respective distribution in the total Multicentre Allergy Study (MAS) population; ${ }^{+}$: sensitisation to cat or mite $\leqslant 3$ yrs and/or concurrent exposure to the

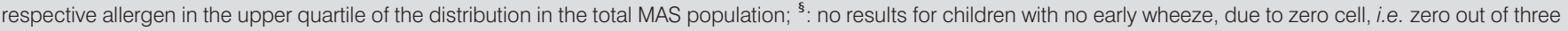
children with no early wheeze, with sensitisation to cat or mite and with low concurrent exposure to the respective allergen had any wheezing episode in puberty. ${ }^{f}$ : forced into the model as potential confounder. The following factors were not significantly associated with wheezing at puberty in the univariate analysis: cord blood lgE; siblings; breast feeding; parental smoking; parental education; early exposure to pets; or early infections. The model for the total population resulted in the following mutually adjusted ORs: early wheeze $(\leqslant 3 \mathrm{yrs})$, adjusted $\mathrm{OR}(95 \% \mathrm{Cl}) 1.87(0.98-3.54), p=0.056$; parental atopy $3.22(1.54-6.72), p=0.002$; early perennial sensitisation $(\leqslant 3$ yrs, ImmunoCAP class II) adjusted OR=4.04 (1.87-8.73), $\mathrm{p} \leqslant 0.001$; and early atopic dermatitis $(\leqslant 2$ yrs) adjusted OR 2.99 (1.52-5.88), $\mathrm{p}=0.002$.

observed and their statistical significance was much stronger among early wheezers than among early nonwheezers. This trend was maintained in the multivariate analyses; perennial sensitisation to indoor (mites, cat and dog) allergens persisted as a very strong predictor of wheezing at 11-13 yrs among early wheezers but no longer showed a significant association among early nonwheezers, and the association of wheezing at 11-13 yrs with parental atopy was three times stronger among early wheezers (adjusted OR 8.32, 95\% CI 2.74-25.20) than among early nonwheezers (adjusted OR 2.48, 95\% CI 1.016.09). However, whereas atopic dermatitis early in life remained a significant predictor for wheezing at 11-13 yrs among early nonwheezers, it was no longer significant in the group of children with early wheeze. In contrast, in the group of early wheezers, male sex emerged as a significant predictor for wheezing at 11-13 yrs. All other early life factors analysed (i.e. cord blood IgE, siblings, breast feeding, parental smoking, parental education, early pets, early allergen exposure and early infections) did not show a significant association with wheezing at 11-13 yrs in either groups (data not shown).
In a model including the whole population, wheezing at 1113 yrs of age was best described by the following factors in early life: early wheeze (adjusted OR 1.87, 95\% CI 0.98-3.54; $\mathrm{p}=0.056$ ) parental atopy (adjusted OR 3.22, 95\% CI 1.54-6.72; $\mathrm{p}=0.002$ ), early indoor (mites, cat and dog) sensitisation (adjusted OR 4.04, 95\% CI 1.87-8.73; $\mathrm{p} \leqslant 0.001$ ) and early AD (adjusted OR 2.99, 95\% CI 1.52-5.88; $\mathrm{p}=0.002$ ).

\section{Prediction of wheezing at 11-13 yrs of age}

Table 4 shows the sensitivity, specificity, and positive and negative predictive values of early-life factors for wheezing at 11-13 yrs of age. Best overall values for all prediction parameters were observed for early sensitisation to indoor (mites, cat and dog) allergens (positive predicted value of $57 \%$ ). When early wheeze was a factor, prediction was even improved to some extent, with a positive predicted value of $75 \%$. Thus, a child with sensitisation to indoor (mites, cat and dog) allergens as well as at least one episode of wheezing before the age of 3 yrs had a probability as high as $75 \%$ of still having wheeze at 13 yrs. The positive predicted value 
TABLE 4 Predictive value of early-life factors for wheezing at age 11-13 yrs

\begin{tabular}{|c|c|c|c|c|c|c|c|c|}
\hline & \multicolumn{4}{|c|}{ No early wheeze ( $\leqslant 3$ yrs) } & \multicolumn{4}{|c|}{ With early wheeze ( $\leqslant 3$ yrs) } \\
\hline & Specificity & Sensitivity & PPV & NPV & Specificity & Sensitivity & PPV & NPV \\
\hline Wheeze ( $\leqslant \mathbf{3}$ yrs) & 74.3 & 47.5 & 22.2 & 90.2 & & & & \\
\hline Male sex & 47.4 & 55.9 & 14.1 & 87.4 & 85.6 & 32.2 & 25.7 & 89.1 \\
\hline Any parental atopy & 49.3 & 79.7 & 19.6 & 94.0 & 86.1 & 40.7 & 31.2 & 90.4 \\
\hline Parental atopic dermatitis & 90.5 & 15.2 & 20.0 & 87.3 & 97.4 & 11.9 & 41.2 & 87.6 \\
\hline Any sensitisation ( $\leqslant 3$ yrs) & 84.9 & 43.4 & 31.1 & 90.5 & 95.3 & 28.3 & 48.4 & 89.4 \\
\hline Food & 89.7 & 23.6 & 27.1 & 87.9 & 97.1 & 16.4 & 47.4 & 87.8 \\
\hline Any inhalant sensitisation ( $\leqslant 3$ yrs) & 92.1 & 33.3 & 40.0 & 89.8 & 96.8 & 22.2 & 52.2 & 88.8 \\
\hline Perennial & 97.4 & 22.2 & 57.1 & 88.8 & 99.1 & 16.7 & 75.0 & 88.3 \\
\hline High allergen exposure ${ }^{\#}$ ( $\leqslant 3$ yrs) & 39.8 & 58.6 & 13.3 & 86.0 & 86.4 & 34.5 & 28.6 & 89.4 \\
\hline $\begin{array}{l}\text { High allergen exposure }+ \text { sensitisation } \\
(\leqslant 3 \mathrm{yrs})\end{array}$ & 98.2 & 13.0 & 53.8 & 87.8 & 99.7 & 9.3 & 83.3 & 87.5 \\
\hline
\end{tabular}

Data are presented as \%. PPV: positive predictive value; NPV: negative predictive value; Ig: immunoglobulin; LRI: lower respiratory illness. ${ }^{\#}$ : exposure to cat or mite allergen $\leqslant 3$ yrs in the upper quartile of the respective distribution in the total Multicentre Allergy Study (MAS) population; ": sensitisation to cat or mite $\leqslant 3$ yrs and concurrent exposure to the respective allergen in the upper quartile of the distribution in the total MAS population.

increased to $83 \%$ when a child with early wheezing and early sensitisation against indoor allergens was also exposed to high concentrations of indoor allergens in the first 3 yrs of life.

\section{DISCUSSION}

In the present analysis of the German MAS cohort, the natural course of wheezing was found to be highly heterogeneous. In an attempt to analyse and classify this heterogeneity, six different longitudinal patterns of wheezing between birth and the age of 13 yrs were described. The present findings add further complexity to the previous classification, which was based on three longitudinal patterns (early, late and persistent wheezers) and covered only the period between birth and 6 yrs of age. It was found that the relative role of early atopic sensitisation and of related risk factors for the long-term prognosis of wheezing change according to the age of wheezing onset. Taken together, the present results support the concept that childhood asthma is more a syndrome, rather than a single, uniform disease [17].

The incidence of wheezing was quite high in the first 3 yrs of life; however, the long-term prognosis of early wheezing was, in most cases, excellent. The vast majority of early wheezers either wheezed no more after the age of 3 yrs (early remittent wheezers) or only in some years (early intermittent wheezers) up to the age of 13 yrs. Only a very small fraction of early wheezers kept on wheezing every single year up to the age of 13 yrs (early persistent wheezers; fig. 1).

The major question of the present study was how to identify, at 3 yrs of age, among early wheezers, those at risk for long-term persistent wheezing. In keeping with outcomes from previous birth cohort studies [4-7], the present study found that a strong predisposition to atopy (a positive family history or early $\operatorname{IgE}$ sensitisation) is the strongest factor predicting whether children wheezing early in life will keep on wheezing until puberty (tables 3 and 4). The present authors have previously shown that lung function at $7 \mathrm{yrs}$ of age is compromised in children with early wheezing combined with early atopic sensitisation [16].

The long-term natural course of wheezing was highly heterogeneous among children who did not wheeze in the first 3 yrs of life. Most of them remained free from wheeze up to the age of 13 yrs, while a minority started wheezing between the age of 3 and 6 yrs (late wheezers) or after the age of 6 yrs (very late wheezers). The question here was how to identify, at 3 yrs of age, among early nonwheezers, those who will start wheezing later, up to the age of 13 yrs. The spectrum of early life atopyrelated risk factors associated with wheezing at puberty was remarkably smaller both qualitatively and quantitatively in early nonwheezers compared with early wheezers (table 3). In a consistent proportion of children, both atopy and wheeze started after 3 or 6 yrs of age. In particular, among very late onset wheezers, the prevalence of sensitisation at $10 \mathrm{yrs}$ of age was three times higher than in the first 3 yrs of life, suggesting that this wheezing pattern was associated with later development of sensitisation. This trend is likely to be maintained at older ages because new atopic sensitisation acquired at school age is also a significant independent predictor of unremitting asthma after puberty $[18,19]$.

By testing just a small number of parameters (sensitisation to indoor allergens, such as mites, cat and dog, and high exposure 
to the same allergens) at 3 yrs of age, a subset of wheezing children with an extremely high probability of wheezing up to age 13 yrs could be identified (table 4 ). In the Tucson cohort study, presence of wheeze at or before 3 yrs of age was also used to predict outcomes at 13 yrs [4]. The present study used most of the "loose" criteria of that study (i.e. wheeze at any stage in the first 3 yrs, plus other factors [4]) but found comparable sensitivities, specificities and negative predictive values to the "stringent" criteria, and even more favourable positive predictive value (table 4). The additional inclusion in the present study of allergen exposure may have contributed to this outcome. The age-dependent variation of risk factors for wheezing at age 11-13 yrs suggests that multiple, distinct algorithms are required to predict persistence of wheezing starting at different ages. This is also in accord with other studies, suggesting that phenotype-specific strategies to predict and prevent asthma in children should be aimed at [20,21].

There are limitations to the present study, for example, the population study is enriched with infants at high risk for atopy, so the results may not be relevant to the general population. Losses in follow-up may have further limited a general value of the present conclusions. Unfortunately, objective evaluation of viral infections on swabs was not available in the MAS. Other studies have found direct evidence of respiratory syncytical virus and rhinovirus infection in infancy to be associated with persistence of asthma in teenagers $[22,23]$.

Recent trials have provided evidence that prolonged antiinflammatory treatment has an impact on infant wheeze but not on its natural history [24, 25]. Generalised, aggressive intervention for secondary and tertiary prevention of wheezing cannot, therefore, be suggested on the basis of the present findings. However, it was observed that a small subset of children with early wheezing, early sensitisation and high exposure to indoor allergens showed a very high positive predictive $(83.3 \%)$ for wheezing at the age of $11-13$ yrs. More studies are necessary in order to ascertain whether this particular small, subset of early wheezers might benefit from preventive strategies yet to be identified.

In conclusion, the present data support the concept that the natural course of wheezing disorders in childhood is quite heterogeneous and that prediction of long-term outcomes may take advantage of not only early diagnosis but also algorithms based on the age of wheezing onset.

\section{ACKNOWLEDGEMENTS}

The present authors would like to thank the study participants, their parents and the collaborators of the MAS group: V. Wahn, M. Groeger and A. Schuster (Düsseldorf, Germany); F. Zepp, I. Bieber and W. Kamin (Mainz, Germany); J. Forster and U. Tacke (Freiburg, Germany); C-P. Bauer (Gaissach, Germany); R. Bergmann (Berlin, Germany). The present authors are indebted to A. Reich (Institute for Social Medicine, Epidemiology and Health Economics, Charité University Medical Centre, Berlin, Germany) for data management and to P. Wagner (Dept of Paediatric Pulmonology and Immunology, Charité University Medical Centre) as the coordinating study nurse in MAS and to C. Clawson for his language expertise.

\section{REFERENCES}

1 Asher MI, Montefort S, Björksten B, et al. Worldwide time trends in the prevalence of symptoms of asthma, allergic rhinoconjunctivitis, and eczema in childhood: ISAAC Phases One and Three repeat multicountry cross-sectional surveys. Lancet 2006; 368: 733-743.

2 Martinez FD. Asthma treatment and asthma prevention: a tale of 2 parallel pathways. J Allergy Clin Immunol 2007; 119: 30-33.

3 Eid NS, National Asthma Education and Prevention Program. Update on National Asthma Education and Prevention Program pediatric asthma treatment recommendations. Clin Pediatr (Phila) 2004; 43: 793-802.

4 Castro-Rodríguez JA, Holberg CJ, Wright AL, Martinez FD. A clinical index to define risk of asthma in young children with recurrent wheezing. Am J Respir Crit Care Med 2000; 162: 1403-1406.

5 Eysink PE, ter Riet G, Aalberse RC, et al. Accuracy of specific $\operatorname{IgE}$ in the prediction of asthma: development of a scoring formula for general practice. Br J Gen Pract 2005; 55 : 125-131.

6 Lieu TA, Quesenberry CP, Sorel ME, Mendoza GR, Leong $\mathrm{AB}$. Computer-based models to identify high-risk children with asthma. Am J Respir Crit Care Med 1998; 157: 1173-1180.

7 Balemans WA, van der Ent CK, Schilder AG, Sanders EA, Zielhuis GA, Rovers MM. Prediction of asthma in young adults using childhood characteristics: development of a prediction rule. J Clin Epidemiol 2006; 59: 1207-1212.

8 Bergmann RL, Bergmann KE, Lau-Schadensdorf S, et al. Atopic diseases in infancy. The German Multicenter Atopy Study (MAS-90). Pediatr Allergy Immunol 1994; 5: Suppl. 6, 19-25.

9 Asher MI, Keil U, Anderson HR, et al. International Study of Asthma and Allergies in Childhood (ISAAC): rationale and methods. Eur Respir J 1995; 8: 483-491.

10 Martinez FD, Wright AL, Taussig LM, Holberg CJ, Halonen M, Morgan WJ. Asthma and wheezing in the first six years of life. The Group of Health Medical Associates. N Engl J Med 1995; 332: 133-138.

11 Illi S, von Mutius E, Lau S, et al. The natural course of atopic dermatitis from birth to age 7 years and the association with asthma. J Allergy Clin Immunol 2004; 113: 925-931.

12 Illi S, von Mutius E, Lau S, et al. Early childhood infectious diseases and the development of asthma up to school age: a birth cohort study. BMJ 2001; 322: 390-395.

13 Kjellman NM, Johansson SG, Roth A. Serum IgE levels in healthy children quantified by a sandwich technique (PRIST). Clin Allergy 1976; 6: 51-59.

14 Wahn U, Lau S, Bergmann R, et al. Indoor allergen exposure is a risk factor for sensitization during the first three years of life. J Allergy Clin Immunol 1997; 99: 763-769.

15 Lau S, Illi S, Sommerfeld C, et al. Early exposure to housedust mite and cat allergens and development of childhood asthma: a cohort study. Lancet 2000; 356: 1392-1397.

16 Illi S, von Mutius E, Lau S, et al. Perennial allergen sensitisation early in life and chronic asthma in children: a birth cohort study. Lancet 2006; 368: 763-770.

17 Editorial. A plea to abandon asthma as a disease concept. Lancet 2006; 368: 705. 
18 Guerra S, Wright AL, Morgan WJ, Sherrill DL, Holberg CJ, Martinez FD. Persistence of asthma symptoms during adolescence: role of obesity and age at the onset of puberty. Am J Respir Crit Care Med 2004; 170: 78-85.

19 Toelle BG, Xuan W, Peat JK, Marks GB. Childhood factors that predict asthma in young adulthood. Eur Respir J 2004; 23: 66-70.

20 Simpson A, Custovic A. The role of allergen avoidance in the secondary prevention of atopic disorders. Curr Opin Allergy Clin Immunol 2005; 5: 223-227.

21 Asher I, Baena-Cagnani C, Boner A, et al. World Allergy Organization guidelines for prevention of allergy and allergic asthma. Int Arch Allergy Immunol 2004; 135: 83-92.
22 Rhodes HL, Thomes P, Sporik R, Holgate ST, Cogswell JJ. A birth cohort study of subjects at risk for atopy: twentytwo-year follow-up of wheeze and atopic status. Am J Respir Crit Care Med 2002; 165: 176-180.

23 Hyvärinen MK, Kotaniemi-Syrjänen A, Reilonen TM, Korhonen K, Korppi MO. Teenage asthma after severe early childhood wheezing: an 11-year prospective follow up. Pediatr Pulmonol 2005; 40: 316-323.

24 Guilbert TW, Morgan WJ, Zeiger RS, et al. Long-term inhaled corticosteroids in preschool children at high risk for asthma. N Engl J Med 2006; 354: 1985-1997.

25 Bisgaard H, Hermansen MN, Loland L, Halkjaer LB, Buchvald F. Intermittent inhaled corticosteroids in infants with episodic wheezing. N Engl J Med 2006; 354: 1998-2005. 